\title{
Etiologia e fatores de risco para a infecção mamária de cabras leiteiras do Estado de São Paulo ${ }^{1}$
}

\section{Etiology and risk factors for mammary infection of dairy goat from São Paulo State}

\author{
Viviani Gomes ${ }^{1 *}$; Mariana Porto Matazo ${ }^{2}$; Cynthia Pereira da Costa e Silva ${ }^{3}$; \\ Vinicius Alvim Passos Baldacim ${ }^{3}$; Sylvia Marquart Fontes Novo ${ }^{3}$; \\ Camila Costa Baccili; Priscilla Anne Melville; ${ }^{4}$ Nilson Roberti Benites ${ }^{5}$
}

\section{Resumo}

O objetivo do trabalho foi identificar os agentes etiológicos e fatores de risco para a mastite carpina. Para tanto, foram colhidas duas alíquotas de 257 amostras de leite, nos meses compreendidos entre Abril a Setembro de 2012, provenientes de 136 cabras da raça Saanen, oriundas de seis criações intensivas, com sistema de ordenha manual e mecânica, localizadas no estado de São Paulo. A primeira alíquota das amostras de leite foi obtida em frascos contendo o conservante bronopol para a contagem de célula somática (CCS) eletrônica, e a segunda em frascos estéreis para o exame bacteriológico. Para avaliação dos fatores de risco, foram aplicados questionários epidemiológicos preenchidos pela equipe de pesquisa mediante observações visuais e inquérito com tratadores e proprietários. Foram realizadas análises univariada e multivariada, utilizando-se a regressão logística múltipla. Observou-se prevalência de $28,79 \%$ de infecção mamária com predomínio de Staphylococcus coagulase negativa (SCN). A mediana da CCS obtida foi de 4,7x10 células por $\mathrm{mL}$ (céls $\mathrm{mL}^{-1}$ ) de leite. $\mathrm{Na}$ análise univariada foi possível observar risco para a infecção mamária nos locais onde a caprinocultura não era a atividade principal da propriedade $(\mathrm{p}=0,03)$; a prova do fundo escuro não era realizada $(\mathrm{p}=0,07)$; não era utilizado o cloro na limpeza dos tetos $(\mathrm{p}=0,29)$; realizava-se limpeza inadequada da sala de ordenha $(\mathrm{p}=0,06)$; observou-se higiene inadequada no processo de ordenha $(\mathrm{p}=0,03)$ e a higiene do ordenhador era inadequada $(\mathrm{p}=0,03)$. A higiene dos tetos, da sala, do processo de ordenha e ordenhador foram os maiores riscos associados à infecção mamária por SCN. Desta forma, apesar das indicações de medidas higiênicas nos programas de qualidade do leite e controle de mastite, a aplicabilidade e conscientização do pessoal envolvido com a cadeia produtiva ainda não estão sensibilizadas. Assim, o treinamento de pessoal seria a principal medida recomendada para o controle da mastite em cabras leiteiras.

Palavras-chave: Contagem de célula somática, exame bacteriológico, mastite, saanen, Staphylococcus coagulase-negativa

\footnotetext{
${ }^{1}$ Prof $^{\mathrm{a}}$, Dept ${ }^{\mathrm{o}}$ de Clínica Médica, Faculdade de Medicina Veterinária e Zootécnica, Universidade de São Paulo, USP, São Paulo, SP. E-mail: viviani.gomes@usp.br

${ }^{2}$ Discente do Curso de Graduação em Medicina Veterinária da Faculdade de Medicina Veterinária e Zootécnica, Universidade de São Paulo, FMVZ/USP, São Paulo, SP. E-mail: mariana_mmz@hotmail.com

${ }^{3}$ Discentes do Curso de Mestrado em Medicina Veterinária do Dept ${ }^{\circ}$ de Clínica Médica, FMVZ/USP, São Paulo, SP. E-mail: cynthiacosta@usp.br; apbvini@hotmail.com; sylvia.novo@usp.br; camila.rcosta@usp.br

${ }^{4}$ Técnica Laboratório do Depto de Medicina Veterinária Preventiva, FMVZ, USP, São Paulo, SP. E-mail: melville@usp.br

${ }^{5}$ Prof., Dept ${ }^{\mathrm{o}}$ de Medicina Veterinária Preventiva, FMVZ, USP, São Paulo, SP. E-mail: benites@usp.br

* Autor para correspondência
} 


\begin{abstract}
The aim of this study was to identify etiologic agents and risk factors for mastitis in dairy goats. For this, two aliquots were collected from 257 milk samples, between April and September, 2012, from 136 Saanen goats from six intensive management farms, with manual and mechanical milking system located in the state of São Paulo. The first aliquot of milk samples was obtained in vials containing preservative bronopol for electronic somatic cell count (SCC), and the second in sterile bottles for bacteriological examination. For risk factors evaluation, epidemiologic questionnaires were performed by the research team by visual observation and survey with handler and owners. Analyzes univariate and multivariate were performed using multiple logistic regression. Was observed prevalence of $28.79 \%$ of mammary infection, and predominance of coagulase-negative Staphylococcus (CNS). The SCC median was $4,7 \times 10^{5}$ cells per $\mathrm{mL}\left(\right.$ cells $\mathrm{mL}^{-1}$ ) of milk. In univariate analysis, was observed risk for mammary infection in places where, the goat was not the main activity of the property $(\mathrm{p}=0.03)$; when the diagnosis of clinical mastitis by proof of dark background was not performed $(\mathrm{p}=0.07)$; when chlorine was not used in the cleaning of the teats $(\mathrm{p}=0.29)$; improper cleaning of the milking parlor $(\mathrm{p}=0.06)$; inadequate hygiene in the milking process $(\mathrm{p}=0.03)$ and inadequate hygiene of the milkers $(\mathrm{p}=03)$. The main group of pathogen isolated in this study was CNS. The biggest risk associated with mammary infection was the hygiene of ceilings, room, milker and also the process of milking resulting from these microorganisms. Thus, despite indications of hygienic measures in the programs of milk quality and mastitis control, the applicability and awareness of employees involved in the production chain of milk goats are not sensitized. Therefore, the personnel training is the principal measure recommended for the control of mastitis in dairy goats.
\end{abstract}

Key words: Bacteriological examination, coagulase-negative, mastitis, saanen, somatic cell count, Staphylococcus

\section{Introdução}

A tecnificação da produção de leite e consumo de derivados lácteos aumentaram os níveis de exigência sobre a qualidade do leite de cabras, exigindo conhecimentos específicos que não podem ser mimetizados da literatura disponível para bovinos, considerando-se particularidades fisiopatológicas entre as espécies. Cabras possuem ciclo de lactação mais curto e secreção láctea do tipo apócrina, que determina padrão de celularidade no leite distinto das vacas (BERGONIER et al., 2003; GOMES et al., 2006).

A mastite é uma doença multifatorial, ocasionada pela combinação de fatores ambientais e de manejo, que podem propiciar condições favoráveis para a instalação de agentes infeccciosos e desencadeamento da doença (PEIXOTO; MOTA; COSTA, 2010). O grupo de bactérias Staphylococcus coagulase-negativa ( $\mathrm{SCN}$ ) são os principais patógenos isolados da glândula mamária de pequenos ruminantes com mastite clínica e subclínica (MCDOUGALL et al., 2002; LANGONI; DOMINGUES; BALDINI, 2006). Estes microrganismos induzem a resposta imune no tecido mamário, que resulta na migração de leucócitos da circulação para a mama e aumento na contagem de células somáticas (CCS) do leite.

Para a prevenção desta enfermidade na caprinocultura leiteira, estudos voltados aos aspectos epidemiológicos são bastante relevantes, sendo o ponto de partida para a adoção de medidas sanitárias dentro da propriedade. Dentre os principais fatores condicionantes da mastite, o manejo de ordenha merece destaque (CONTRERAS et al., 2007; PEIXOTO et al., 2012). No entanto, poucos estudos foram realizados com foco na cadeia epidemiológica da mastite em pequenos ruminantes. Dessa forma, o objetivo desta pesquisa foi determinar a etiologia e fatores de risco relacionados ao manejo, equipamento e cuidados de higiene no processo de ordenha, para a infecção mamária e altas contagens de células somáticas no leite de cabras. 


\section{Material e Métodos}

Foi realizado estudo transversal no Outono e Primavera de 2012, em seis capris leiteiros (A a F), dos quais três adotavam o sistema de ordenha manual e as outras três o sistema de ordenha mecânico, localizados nas cidades Ibiúna, Joanópolis, Jaguariúna, Mogi das Cruzes, Jundiaí e São Paulo capital (Figura 1). Foram obtidas
270 amostras de leite, antes da ordenha da tarde, provenientes de 136 fêmeas da raça Saanen, adultas, em diferentes estágios de lactação e número de partos. Duas cabras apresentavam metade mamária perdida e treze amostras de leite apresentaram volume insuficiente para a CCS eletrônica, desta forma, foram processadas 257 amostras de leite de cabras.

Figura 1. Localização dos capris leiteiros selecionados para avaliação da etiologia e fatores de risco para mastite em cabras leiteiras.

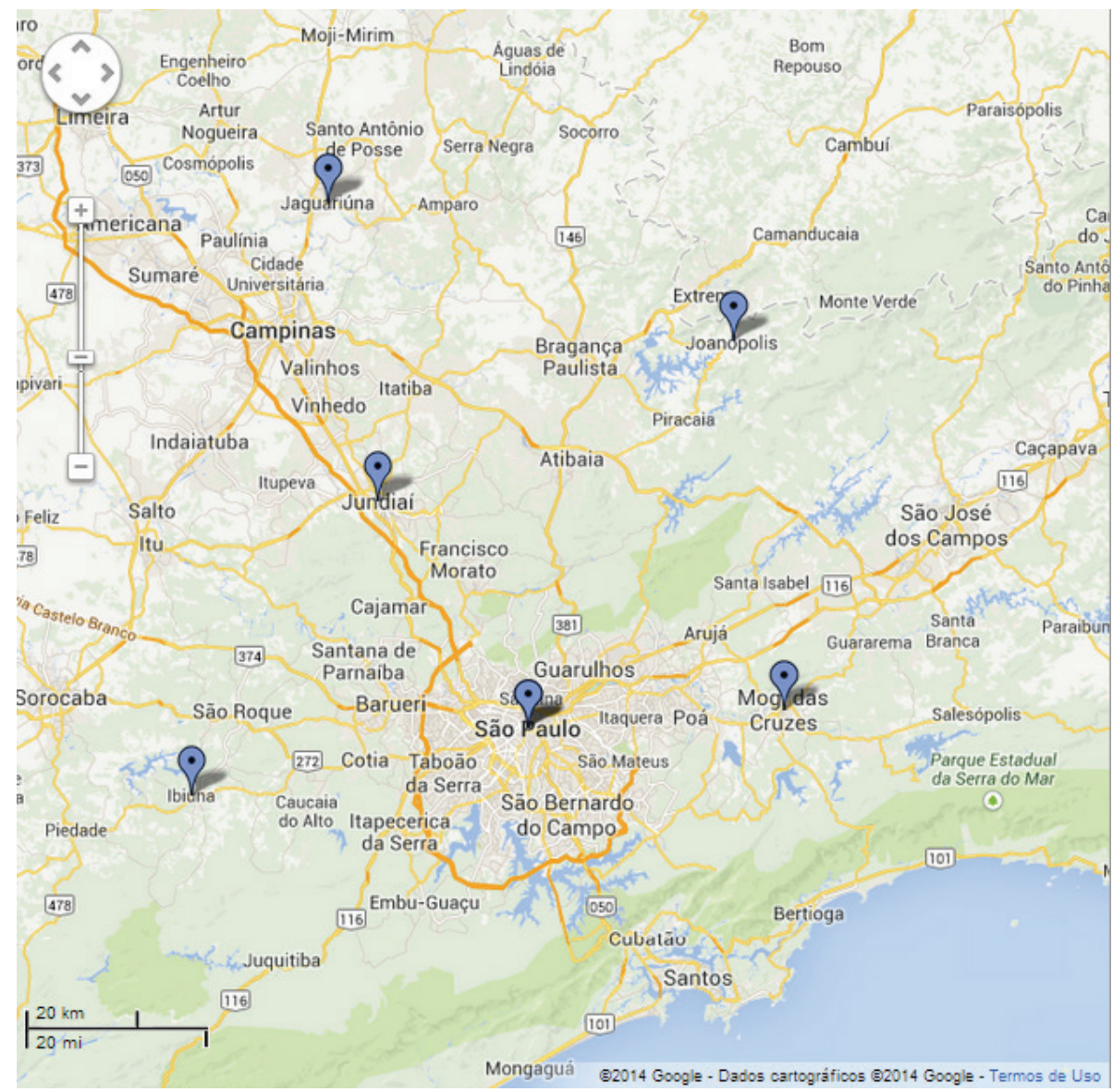

Fonte: Google Maps (2014).

Inicialmente, o úbere foi higienizado, retirandose as sujidades depositadas sobre a pele da glândula e dos tetos. Em seguida, realizou-se a lavagem dos tetos com solução de hipoclorito a $2 \%$, e secagem com papel toalha descartável. Após desprezar os primeiros três jatos de leite, foi realizada a antissepsia do óstio (ductus papilaris), friccionando algodão embebido em álcool 70\%.

Foram colhidas duas alíquotas das amostras para a contagem de células somáticas (CCS) e exame bacteriológico. A primeira alíquota foi 
obtida em frascos plásticos contendo microtabletes de conservante a base de bronopol (2-bromo-2 nitropropane-1,3-diol) e natamycin para contagem de células somáticas em aparelho eletrônico baseado no princípio de citometria de fluxo (Somacount $300^{\circledR}$, Bentley Instruments) na Clínica do leite Escola Superior de Agricultura Luiz de Queiroz (GOMES et al., 2006).

A segunda alíquota foi obtida em frascos estéreis com tampa de rosca, que permaneceu aberto pelo período máximo de cinco segundos, de acordo com as recomendações do National Mastitis Council (1996). As amostras foram transportadas sob refrigeração ao laboratório e congeladas a $-20^{\circ} \mathrm{C}$ até o momento da realização do exame bacteriológico no Laboratório de Bacteriologia do Departamento de Medicina Veterinária Preventiva da FMVZ-USP.

As amostras de leite de cabras foram semeadas em placas de Petri contendo ágar-sangue de carneiro (5\%), utilizando-se o método de semeadura por esgotamento em estrias, e incubadas $\left(37^{\circ}\right.$ C por 24 e 72 horas). A identificação do grupo SCN foi realizada pela avaliação macroscópica e microscópica das colônias, provas da catalase e coagulase (DELLA LIBERA et al., 2010); para Staphylococcus aureus também foram utilizados os sistemas de identificação RapID ${ }^{\circledR}$ (Remel - Oxóid); para Corynebacterium spp. foi realizada pela prova da catalase e identificação macro e microscópica das colônias.

Para avaliação dos fatores de risco, foram aplicados dois questionários epidemiológicos preenchidos pela equipe de pesquisa mediante observações visuais e inquérito com tratadores e proprietários. Os temas abordados possuíam relação com o manejo, equipamento e cuidados de higiene no momento da ordenha. O primeiro foi aplicado às propriedades que adotavam ordenha manual e mecânica, composto por 11 questões relacionadas ao manejo e cuidados de higiene no momento na ordenha. O segundo, direcionado para as que adotavam sistema de ordenha automatizada possuía 14 questões relacionadas ao estado do equipamento de ordenha mecânica.

Para determinação do status sanitário dos rebanhos e higidez da glândula mamária foram utilizados dois indicadores de mastite: exame bacteriológico e celularidade do leite. Foram calculadas as frequências de crescimento bacteriano e das amostras de leite com alta celularidade (CCS $>1 \times 10^{6}$ cels $\mathrm{mL}^{-1}$ ) em cada propriedade avaliada.

Para a avaliação dos fatores de risco foram utilizados os questionários epidemiológicos aplicados nas propriedades. Foram realizadas análises univariada e multivariada, considerando-se os resultados obtidos a partir das metades mamárias. $\mathrm{Na}$ análise univariada cada variável independente foi cruzada com a variável dependente - presença de infecção mamária. As que apresentaram um valor de $\mathrm{p} \leq 0,2$ pelo teste de qui-quadrado ou teste exato de Fisher (ZAR, 1999), foram selecionadas e oferecidas para análise multivariada, utilizandose a regressão logística múltipla (HOSMER; LEMESHOW, 2000). O nível de significância adotado na análise múltipla de 5\%. Para análise estatística foi usado o programa SPSS Statistic 13.0.

$\mathrm{O}$ projeto de pesquisa que deu origem a este artigo foi aprovado pela Comissão de Bioética da FMVZ/USP sob número 827/2006.

\section{Resultados}

Das 257 amostras de leite, 74 (28,79\%) apresentaram crescimento positivo no exame bacteriológico.

$\mathrm{O}$ principal agente etiológico associado à infecção intramamária em cabras leiteiras foi o $\mathrm{SCN}$, isolado em 67/74 (90,54\%) amostras de leite com crescimento bacteriano. Corynebacterirum spp. foi isolado em 4/74 (5,40\%) e Staphylococcus aureus em 3/74 (4,05\%). A distribuição destes patógenos entre os sistemas de ordenha manual e mecânico 
foram semelhantes. No sistema de ordenha manual a frequência de isolamento bacteriano variou de 19,44 a 38,70\%; e na ordenha mecânica de 22,22 a $40,00 \%$ (Tabela 1$)$.

A mediana da CCS foi de $4,79 \times 10^{5}$ células $\mathrm{mL}^{-1}$ de leite. Das 257 amostras analisadas, 99
$(38,52 \%)$ delas apresentaram alta celularidade (CCS $>1,0 \times 10^{6}$ céls $\left.\mathrm{mL}^{-1}\right)$ (ZENG, 1996). Os valores medianos de CCS variaram de 5,63 a $30,92 \times 10^{5}$ células $\mathrm{mL}^{-1}$ de leite no sistema de ordenha manual; e 2,37 a $16,88 \times 10^{5}$ células céls $\mathrm{mL}^{-1}$ na ordenha automatizada (Tabela 2).

Tabela 1. Frequências de isolamentos bacterianos e etiologia da mastite em cabras leiteiras criadas em seis propriedades leiteiras que adotavam sistema de ordenha manual e mecânica.

\begin{tabular}{|c|c|c|c|c|c|c|c|}
\hline \multirow{2}{*}{$\begin{array}{c}\text { Sistema de } \\
\text { ordenha }\end{array}$} & \multirow{2}{*}{$\begin{array}{c}\text { Id. } \\
\text { Propriedade }\end{array}$} & \multirow{2}{*}{$\begin{array}{c}\text { No. de } \\
\text { amostras }\end{array}$} & \multicolumn{3}{|c|}{ Etiologia } & \multicolumn{2}{|c|}{ Crescimento bacteriano } \\
\hline & & & S. aureus & $\mathrm{SCN}$ & Corynebacterium spp. & No. & $\%$ \\
\hline \multirow[t]{3}{*}{ Manual } & $\mathrm{A}$ & 36 & 0 & 7 & 0 & 7 & 19,44 \\
\hline & $\mathrm{B}$ & 62 & 1 & 23 & 0 & 24 & 38,70 \\
\hline & $\mathrm{C}$ & 8 & 1 & 2 & 0 & 3 & 37,50 \\
\hline \multirow[t]{3}{*}{ Mecânico } & $\mathrm{D}$ & 81 & 0 & 14 & 4 & 18 & 22,22 \\
\hline & $\mathrm{E}$ & 35 & 1 & 13 & 0 & 14 & 40,00 \\
\hline & $\mathrm{F}$ & 35 & 0 & 8 & 0 & 8 & 22,86 \\
\hline TOTAL & & 257 & 3 & 67 & 4 & 74 & 28,79 \\
\hline
\end{tabular}

Id. Identificação; S.aureus: Staphylococcus aureus; SCN: Staphylococcus coagulase negativa.

Fonte: Elaboração dos autores.

Tabela 2. Contagem de células somáticas (CCS) eletrônica no leite de cabras provenientes de seis propriedades leiteiras que adotavam sistema de ordenha manual e mecânico.

\begin{tabular}{cccccccccccc}
\hline Sistema de & & N Amostral & \multicolumn{8}{c}{ CCS (x10 células/mL) } \\
ordenha & & $(\mathrm{n}=257)$ & Mediana & Min & Máx & Méd. & DP & $<10,0$ & $\%$ & $>10,0$ & $\%$ \\
\hline \multirow{3}{*}{ Manual } & $\mathrm{A}$ & 36 & 5.6 & 0.4 & 100.0 & 5.7 & 4.4 & 21 & 58.3 & 15 & 41.6 \\
& $\mathrm{~B}$ & 62 & 1.9 & 0.1 & 82.5 & 1.8 & 6.2 & 45 & 72.5 & 17 & 27.4 \\
& $\mathrm{C}$ & 8 & 30.9 & 4.7 & 68.1 & 21.5 & 3.1 & 2 & 25.0 & 6 & 75.0 \\
\hline \multirow{3}{*}{ Mecânico } & $\mathrm{D}$ & 81 & 7.1 & 0.1 & 99.9 & 6.5 & 4.6 & 47 & 58.0 & 34 & 41.9 \\
& $\mathrm{E}$ & 35 & 1.7 & 0.2 & 62.8 & 2.4 & 4.4 & 15 & 42.8 & 20 & 57.1 \\
& $\mathrm{~F}$ & 35 & 2.4 & 0.2 & 99.9 & 14.2 & 5.3 & 28 & 80.0 & 7 & 20.0 \\
\hline
\end{tabular}

Mín - mínimo; Máx - máximo; Méd - média; DP - desvio-padrão.

Fonte: Elaboração dos autores.

Foram investigados os fatores de risco relacionados à presença da infecção bacteriana das metades mamárias de cabras leiteiras. Observaramse variações no manejo de ordenha entre as seis propriedades examinadas, no entanto, a manutenção e higienização do equipamento de ordenha eram semelhantes entre os capris que usavam sistema automatizado (Tabela 3). Dessa forma, optou-se pela estimativa do grau de risco considerando-se apenas os aspectos relacionados ao manejo de ordenha nas seis propriedades examinadas.

Os capris realizavam duas ordenhas ao dia e todos adotavam linha de ordenha dos animais hígidos aos que apresentavam mastite. Uma propriedade $(16,6 \%)$ não usava a prova de fundo escuro para a detecção da mastite clínica e adoção de medidas 
preventivas. Somente os tetos eram lavados antes do processo de ordenha, com água $(33,3 \%)$, iodo $(16,7 \%)$ ou cloro $(50 \%)$, em seguida, eram secos com papel toalha $(83,4 \%)$ ou pano $(16,6 \%)$. O pósdipping era realizado com iodo em 5/6 $(83,4 \%)$ dos capris leiteiros, porém um dos capris examinados não adotava essa medida. É válido ressaltar que o uso de iodo no pré-dipping pode gerar resíduos no leite, decorrente da contaminação da superfície do teto ou absorção do produto e eliminação durante o processo de síntese da secreção láctea (FLACHOWSKY et al., 2014).

Todas as propriedades realizavam tratamento das fêmeas doentes com antibióticos durante a lactação e descartavam o leite dos animais em tratamento, no entanto, o emprego de antibióticos no processo de secagem era realizado em 5/6 (Tabela 4).

Tabela 3. Frequências das variáveis e categorias usadas para avaliação dos fatores de risco relacionados à manutenção e higienização do equipamento de ordenha em capris leiteiros.

\begin{tabular}{|c|c|c|c|}
\hline Variáveis & Categorias & Capris (no.) & Frequências $(\%)$ \\
\hline \multirow{2}{*}{ Tipo de ordenha } & Mecânica & 03 & 50,0 \\
\hline & Manual & 03 & 50,0 \\
\hline \multirow{2}{*}{ Idade do equipamento de ordenha } & De 5 a 10 anos & 01 & 33,3 \\
\hline & Acima de 10 anos & 02 & 66,6 \\
\hline \multirow{2}{*}{ Frequência de manutenção } & Semestral & 01 & 33,3 \\
\hline & Esporádico & 02 & 66,6 \\
\hline Tem disponibilidade de água quente & Sim & 03 & 100,0 \\
\hline Uso de detergente na limpeza & Sim & 03 & 100,0 \\
\hline Uso de sanitizante na limpeza & Sim & 03 & 100,0 \\
\hline \multirow{2}{*}{ Limpeza do equipamento de ordenha } & Automático & 02 & 66.6 \\
\hline & Manual & 01 & 33.3 \\
\hline Deficiência de limpeza dos pulsadores & Não & 03 & 100,0 \\
\hline Estado inadequado do equipamento de ordenha & Não & 03 & 100,0 \\
\hline $\begin{array}{l}\text { Presença de rachaduras e fissuras nas partes de } \\
\text { borracha do equipamento de ordenha }\end{array}$ & Não & 03 & 100,0 \\
\hline
\end{tabular}

Fonte: Elaboração dos autores. 
Tabela 4. Frequências das variáveis e categorias usadas para avaliação dos fatores de risco relacionados ao manejo e cuidados de higiene durante a ordenha em capris leiteiros.

\begin{tabular}{lccc}
\hline Variáveis & Categorias & Capris (no.) & Frequências (\%) \\
\hline Frequência de ordenha & Duas vezes & 06 & 100,0 \\
Linha de ordenha & Sim & 06 & 100,0 \\
Uso da prova de fundo Escuro & Sim & 05 & 83,4 \\
Lavagem dos tetos pré ordenha & Não & 01 & 16,6 \\
Lavagem de toda a mama & Sim & 06 & 100,0 \\
& Não & 06 & 100,0 \\
Desinfetante usado na lavagem dos tetos & Somente água & 02 & 33,3 \\
& Iodo & 01 & 16,7 \\
Material utilizado para secagem dos tetos & Cloro & 03 & 50,0 \\
& Papel toalha & 05 & 83,4 \\
Uso do pós-dipping & Pano & 01 & 16,6 \\
Medicação para mastite em fêmeas lactantes & Sim & 05 & 83,4 \\
Medicação para mastite em fêmeas na fase seca & Não & 01 & 16,6 \\
& Sim & 06 & 100,0 \\
\hline
\end{tabular}

Fonte: Elaboração dos autores.

$\mathrm{Na}$ análise univariada considerando-se as variáveis relacionadas no tabela 03 que apresentaram $\mathrm{p}<0,2$, observou-se risco para a infecção mamária quando a caprinocultura não era a atividade principal da propriedade $(\mathrm{p}=0,03)$; quando o diagnóstico da mastite clínica pela prova do fundo escuro não era realizada $(p=0,07)$; quando o cloro não era utilizado na limpeza dos tetos $(\mathrm{p}=0,29)$; limpeza inadequada da sala de ordenha $(\mathrm{p}=0,06)$; higiene inadequada no processo de ordenha $(p=0,03)$ e higiene inadequada do ordenhador $(\mathrm{p}=0,03)$, identificados por observação visual (Tabela 5).

$\mathrm{Na}$ análise multivariada foram testados vários modelos na regressão logística, apenas a caprinocultura não ser a atividade principal, a higiene no processo de ordenha e a higiene do ordenhador apresentaram significância, sendo o valor de $\mathrm{p}=0,03$ e Odds ratio $=0,526$. 
Tabela 5. Análise univariada com a distribuição das variáveis relacionadas ao manejo de ordenha associadas às infecções bacterianas em cabras leiteiras.

\begin{tabular}{|c|c|c|c|c|c|c|}
\hline \multirow{3}{*}{ Variáveis } & \multicolumn{6}{|c|}{ Manejo de ordenha } \\
\hline & \multirow{2}{*}{$\begin{array}{l}\text { Categoria } \\
\text { basal }\end{array}$} & \multirow{2}{*}{$\begin{array}{l}\text { Categoria } \\
\text { de risco }\end{array}$} & \multirow[t]{2}{*}{ Significância } & \multirow[t]{2}{*}{ OR } & \multicolumn{2}{|c|}{$\begin{array}{l}95 \% \text { Intervalo de } \\
\text { confiança }\end{array}$} \\
\hline & & & & & Menor & Maior \\
\hline $\begin{array}{l}\text { Caprinocultura como atividade } \\
\text { principal }\end{array}$ & Sim & Não & $0,03 *$ & 0,526 & 0,297 & 0,933 \\
\hline Piso das instalações & $\begin{array}{l}\text { Piso suspenso } \\
\text { ripado }\end{array}$ & Chão & 0,76 & 1,098 & 0,608 & 1,982 \\
\hline Tipo de ordenha & Mecânica & Manual & 0,38 & 0,789 & 0,465 & 1,341 \\
\hline $\begin{array}{l}\text { Identificação da Mastite pela Prova de } \\
\text { Fundo Escuro }\end{array}$ & Sim & Não & $0,07 *$ & 0,574 & 0,316 & 1,043 \\
\hline Uso iodo limpeza tetos & Não & Sim & 0,44 & 2,101 & 0,512 & 8,620 \\
\hline Uso de cloro na limpeza dos tetos & Sim & Não & $0,29 *$ & 0,752 & 0,442 & 1,278 \\
\hline $\begin{array}{l}\text { Uso somente de água na limpeza dos } \\
\text { tetos }\end{array}$ & Não & Sim & 0,49 & 1,209 & 0,706 & 2,069 \\
\hline Material usado para secagem dos tetos & Papel toalha & Pano & 0,44 & 0,476 & 0,116 & 1,952 \\
\hline Pós dipping & Não & Sim & 0,34 & 1,500 & 0,651 & 3,457 \\
\hline Uso antibiótico período seco & Sim & Não & 0,43 & 0,598 & 0,164 & 2,182 \\
\hline Limpeza da sala de ordenha & Adequada & Inadequada & $0,06^{*}$ & 1,759 & 0,971 & 3,188 \\
\hline Higiene do Processo de ordenha & Adequada & Inadequada & $0,03^{*}$ & 1,901 & 1,072 & 3,372 \\
\hline Higiene do ordenhador & Adequada & Inadequado & $0,03 *$ & 1,901 & 1,072 & 3,372 \\
\hline
\end{tabular}

Fonte: Elaboração dos autores.

\section{Discussão}

Foi obervado predomínio de SCN nas amostras de leite caprino com isolamento bacteriano positivo. Este dado também foi encontrado por Poutrel (1984), Maisi e Riipinen (1991), Bergonier et al. (2003), Neves et al. (2010) e Peixoto et al. (2012). Este grupo de microrganismos é extremamente importante como agentes patogênicos da mastite caprina infecciosa, pertencem a microbiota da pele dos tetos e podem penetrar a glândula mamária por via ascendente. (BERGONIER et al., 2003).

A alta incidência de SCN foi observada em propriedades que adotavam tratamento intensificado de Staphylococcus coagulase positiva, pois SCN possuem habilidade de produzir plasmídeos que possuem genes que conferem resistência aos antibióticos, que confere maior incidência e prevalência dos $\mathrm{SCN}$ em rebanhos com alto controle leiteiro (PYÖRÄLÄ, 2009). As propriedades examinadas usavam antibióticos para tratamento da mastite durante a lactação e cinco delas realizavam o tratamento no período de secagem, porém o estabelecimento desses protocolos, geralmente estabelecidos pelos tratadores sem a participação do Médico veterinário, é dificultado pela escassez de informações específicas para cabras. Antibióticos intramamários indicados para caprinos e ovinos são indisponíveis no mercado, provavelmente pela falta de testes clínicos e informações básicas sobre os princípios ativos e doses recomendadas para essa espécie (MAVROGIANNI et al., 2011). Esta prática pode resultar em resistência bacteriana aos antimicrobianos.

As taxas de infecção mamária observada por Neves et al. (2010) e Peixoto et al. (2012) na região nordeste foram de 11,49 e 19,44\%, respectivamente, inferior ao encontrado nesta pesquisa nos rebanhos 
paulistas (28,79\%). Apesar disso, a média da CCS encontrada na Paraíba por Neves et al. (2010) foi superior $\left(1,39 \times 10^{6}\right.$ células $\left.\mathrm{mL}^{-1}\right)$ a observada em São Paulo $\left(0,48 \times 10^{6}\right.$ células $\left.\mathrm{mL}^{-1}\right)$.

As diferenças entre as raças, sistema de criação e tipo de exploração, além do sistema e manejo de ordenha empregado entre os estudos realizados na região nordeste (PAAPE et al., 2007; NEVES et al., 2010; PEIXOTO et al., 2012) e São Paulo dificultam a comparação entre as frequências de isolamento bacteriano e fatores de risco das regiões brasileiras avaliadas. As propriedades avaliadas no nordeste adotavam sistema de criação predominantemente semi-intensiva ou extensiva, com tipo de exploração mista e não especificaram o padrão racial adotado. No entanto, por estas características pode-se pressupor que usaram animais mestiços de raças nativas da região nordeste, que prejudica a aplicação das informações obtidas para os fatores de risco para a infecção mamária no estado de São Paulo, que possui predomínio da raça Saanen adotando sistema de criação intensivo.

Dentre os questionamentos usados no inquérito epidemiológico para identificação dos fatores de risco entre os trabalhos do nordeste e São Paulo pode-se verificar que a limpeza da sala de ordenha foi fator de risco em comum entre esta pesquisa e o trabalho realizado na Paraíba por Neves et al. (2010). Além disso, os outros fatores de risco observados na presente pesquisa são compatíveis com a presença do SCN nas infecções mamárias de cabras. Estes fatores estão relacionados à transmissão de microrganismos infecciosos no processo de ordenha, tais como: identificação de casos clínicos pela prova de fundo escuro, processo fundamental para identificação e tratamento dos doentes, ordem de ordenha e isolamento de animais enfermos; limpeza durante o processo de ordenha e hábitos de higiene do ordenhador.

Oliveira et al. (2011) também verificou que a identificação da mastite clínica pela prova de fundo escuro era um fator de risco para altas contagens de colônias bacterianas no tanque de expansão de capris leiteiros da Paraíba.

Neves et al. (2010) também verificaram que quando a caprinocultura não é a atividade principal da propriedade, os animais são mais susceptíveis as infecções mamárias. Estes autores justificaram este achado pela associação à utilização das instalações, técnicas e manejo não adequados para a produção de leite caprino nas propriedades, bem como a assistência técnica deficiente, baixo nível de organização, falta de controle sanitário efetivo e falta de mão de obra especializada.

Lima Júnior, Nader e Vianni (1995) estudaram os fatores de risco para mastite subclínica em cabras no estado do Rio de Janeiro, usando apenas a prova do California Mastitis Test (CMT) como critério diagnóstico. Nesse estudo, os fatores de risco relacionados à presença de CMT $2+$ e $3+$ foram: sistema intensivo de criação em confinamento com elevada densidade de animais por unidade de área; piores condições de higiene; tendência em criar outras espécies de ruminantes. Estes achados foram semelhantes ao observado no presente estudo, apesar do método empregado para a identificação da infecção mamária ter sido diferente. A semelhança entre os sistemas de criação predominantemente intensivos com o uso de raças mais especializadas para a produção leiteira deve ter colaborado com tal resultado. Por outro lado, os referidos autores citaram, que a utilização de um único pano para lavagem do úbere de todas as cabras durante a ordenha foi considerado um fator de risco. Nesta pesquisa, nenhuma das propriedades estudadas realizava tal procedimento, porém a propriedade $\mathrm{C}$ que adotava sistema de ordenha manual adotava a secagem dos tetos com pano. A frequência de infecção mamária nesta propriedade foi de $37,50 \%$, valor superior ao observado nas propriedades A, D e F.

\section{Conclusão}

SCN foi o principal grupo bacteriano isolado do leite de cabras. A higiene dos tetos, da sala de 
ordenha, do processo de ordenha e ordenhador foram os maiores riscos associados às infecções mamárias. Dessa forma, apesar das indicações de medidas higiênicas no controle da mastite caprina, a aplicabilidade e conscientização do pessoal envolvido com a cadeia produtiva do leite de cabras ainda não estão sensibilizadas. Assim, o treinamento de pessoal seria a principal medida recomendada para o controle da mastite em cabras leiteiras.

\section{Agradecimentos}

À Fundação de amparo a pesquisa do estado de São Paulo (FAPESP) pela concessão de auxílio financeiro para a realização desta pesquisa (Proc. 2011/18502-7).

\section{Referências}

BERGONIER, D.; CRÉMOUX, R.; RUPP, R.; LAGRIFFOUL, G.; BERTHELOT, X. Mastitis of dairy small ruminants review. Veterinary Research, Ghent, v. 34, p. 689-716, 2003.

CONTRERAS, A.; SIERRA, D.; SÁNCHEZ, A.; CORRALES, J. C.; MARCO, J. C.; PAAPE, M. J.; GONZALO, C. Mastitis in small ruminant. Small Ruminant Research, Amsterdam, v. 6, n. 1-2, p. 145-153, 2007.

DELLA LIBERA, A. M. M. P.; BLAGITZ, M. G.; SOUZA, F. N.; BATISTA, C. F.; AZEDO, M. R.; BENITES, N. R.; MELVILLE, P. A.; GOMES, V. Antimicrobial susceptibility of coagulase-negative staphylococci isolated from meat-producing ewes with mastitis. Arquivo Brasileiro de Medicina Veterinária e Zootecnia, Belo Horizonte, v. 62, n. 6, p. 1499-1502, 2010.

FLACHOWSKY, G.; FRANKE, K.; MEYER, U.; LEITERER, M.; SCHONE, F. Influencing factors on iodine content of cow milk. Europian Journal of Nutrition, Bethesda, v. 53, n. 2, p. 351-365, 2014.

GOMES, V.; DELLA LIBERA, A. M. M. P.; MADUREIRA, K. M.; ARAÚJO, W. P. Effect of the stage of lactation on somatic cell counts in healthy goats (Caprae hircus) breed in Brazil. Small Ruminant Research, Amsterdam, v. 64, n. 1, p. 30-34, 2006.

GOOGLE MAPS. Mapa da localização das cidades onde estavam localizados os Capris leiteiros estudados. [S.1.: s.n.], 2014. Disponível em: <http://maps.google.com.br/ $\mathrm{maps} / \mathrm{ms}$ ?msid $=204778645287223502805.0004 \mathrm{fa} 8 \mathrm{e} 42 \mathrm{a}$ $\mathrm{e} 58350 \mathrm{f} 112 \& \mathrm{msa}=0 \& 1 \mathrm{l}=-22.634293,-45.637207 \& \mathrm{spn}=$ $6.507092,12.491455 \&$ iwloc $=0004 \mathrm{fa} 8 \mathrm{e} 4507 \mathrm{~d} 1 \mathrm{f} 4718 \mathrm{e} 2>$. Acesso em: 29 maio 2014.

HOSMER, D. W.; LEMESHOW, S. Applied logistic regression. New York: John Wiley and Sons, 2000. 375 p.

LANGONI, H.; DOMINGUES, P. F.; BALDINI, S. Mastite caprina: seus agentes e sensibilidade frente a antimicrobianos. Revista Brasileira de Ciência Veterinária, Rio de Janeiro, v. 13, n. 1, p. 51-54, 2006.

LIMA JÚNIOR, A. D.; NADER, F. A.; VIANNI, M. C. E. Fatores condicionantes da mastite subclínica em criatórios do Rio de Janeiro. Arquivo Brasileiro de Medicina Veterinária e Zootecnia, Belo Horizonte, v. 47, n. 4, p. 463-467, 1995.

MAISI, P.; RIIPINEN, I. Pathogenicity of different species of staphylococci in caprine udder. British Veterinary Journal, v. 147, n. 2, p. 126-132, 1991.

MAVROGIANNI, V. S.; PAPADOPOULOS, E.; FRAGKOU, I. A.; GOUGOULIS, D. A.; VALASI, I.; ORFANOU, D. C.; PTOCHOS, S.; GALLIDIS, E.; FTHENAKIS, G. C. Administration of a long-acting antiparasitic to pre-pubertal ewe-lambs in Greece results in earlier reproductive activity and improved reproductive performance. Veterinary Parasitology, Amsterdam. v. 177, n. 1-2, p. 139-144, 2011.

McDOUGALl, S.; PANKEY, W.; DELANEY, C.; BARLOW, J.; MURDOUGH, P. A.; SCRUTON, D. Prevalence and incidence of subclinical mastitis in goats and dairy ewes in Vermont, USA. Small Ruminant Research, Amsterdam, v. 46, n. 2, p. 115-121, 2002.

NEVES, P. B.; MEDEIROS, E. S.; SÁ, V. V.; CAMBOIM, E. K. A.; GARINO JÚNIOR, F.; MOTA, R. A.; AZEVEDO, S. S. Perfil microbiológico, celular e fatores de risco associados à mastite subclínica em cabras no semiárido da Paraíba. Pesquisa Veterinária Brasileira, Seropédica, v. 30, n. 5, p. 379-384, 2010.

OLIVEIRA, C. J. B.; HISRICH, E. R.; MOURA, J. F. P.; GIVISIEZ, P. E. N.; COSTA, R. G.; GEBREYES, W. A. On farm risk factors associated with goat milk quality in Northeast Brazil. Small Ruminant Research, Amsterdam, v. 98, n. 1-3, p. 64-69, 2011.

PAAPE, M. J.; WIGGANS, G. R.; BANNERMAN, D. D.; THOMAS, D. L.; SANDERS, A. H.; CONTRERAS, A.; MORONI, P.; MILLER, R. H. Monitoring goat and sheep milk somatic cell counts. Small Ruminant Research, Amsterdam, v. 68, n. 1-2, p.114-125, 2007. 
PEIXOTO, R. M.; AMANSO, E. S.; CAVALCANTE, M. B.; AZEVEDO, S. S.; PINHEIRO JUNIOR, J. W.; MOTA, R. A.; COSTA, M. M. Fatores de risco para mastite infecciosa em cabras leiteiras criadas no estado da Bahia. Arquivos Instituto Biológico, São Paulo, v. 79, n. 1, p. 101-105, 2012.

PEIXOTO, R. M.; MOTA, R. A.; COSTA, M. M. Mastite em pequenos ruminantes no Brasil. Pesquisa Veterinária Brasileira, Seropédica, v. 30, n. 9, p. 754-762, 2010.

POUTREL, B. Udder infection of goats by coagulasenegative staphylococci. Veterinary Microbiology, Barcelona, v. 9, n. 2, p. 131-137, 1984.
PYÖRÄLÄ, S.; TAPONEN, S. Coagulase-negative staphylococci- Emerging mastitis pathogens. Veterinary Microbiology, Barcelona, v. 134, n. 1-2, p. 3-8, 2009.

ZAR, J. H. Biostatistical analysis. 4. ed. New Jersey: Prentice Hall, 1999. 663 p.

ZENG, S. S. Comparisons of goat milk standars of analyses somatic cell count, fat, and protein in goat milk. Small Ruminant Research, Amsterdam, v. 21, n. 3, p. 221-225, 1996. 
